\title{
A história não ensinada
}

\section{The history not taught}

\author{
Janaina Morelli Dias \\ Graduanda em Publicidade e Propaganda na \\ Universidade Federal do Rio de Janeiro \\ morellidias@gmail.com \\ https://orcid.org/0000-0002-5044-8845
}

\author{
Marta Simões Peres \\ Professora Adjunta do departamento de arte corporal \\ da Universidade Federal do Rio de Janeiro \\ martasperes@gmail.com \\ https://orcid.org/0000-0003-1046-2551
}

\begin{abstract}
Resumo. Essa análise tem como objetivo observar o conhecimento existente entre os docentes, discentes e servidores da Universidade Federal do Rio de Janeiro (Campus Praia Vermelha) no que diz respeito ao passado do local onde eles atuam. Esta investigação ancora-se no pressuposto de que esse conhecimento não é passado de geração a geração pelos professores e alunos. Volta-se, ainda, à aplicabilidade e à real função social da perpetuação desse saber, uma vez que a história nos mostra certos estigmas ligados à saúde mental. A metodologia consistiu em pesquisa bibliográfica a partir de artigos e livros e entrevista com pessoas que ocupam o local de diversas formas. As conclusões mostraram que há uma defasagem nas informações, mas existem recursos e eles devem ser pensados em prol da relação universidade-sociedade.
\end{abstract}

Palavras-chave: História. Saúde Mental. Ocupação. Universidade.

Abstract. This analysis aims to observe the existing knowledge among the professors, students and servers of the Federal University of Rio de Janeiro (Campus Praia Vermelha) with regard to the past of the place where they work. 
This investigation is based on the assumption that this knowledge is not passed on from generation to generation by teachers and students. It also turns to the applicability and the real social function of the perpetuation of this knowledge, since history shows us certain stigmas linked to mental health. The methodology consisted of bibliographic research based on articles and books and interviews with people who occupy the place in different ways. The conclusions showed that there is a gap in the information, but there are resources and they should be considered in favor of the university-society relationship.

Keywords: History. Mental health. Occupation. University.

Recebido: 01/10/2017 Aceito: 27/10/10 Publicado: 05/11/2017

\title{
1. Introdução
}

Mais um semestre. Novos alunos e novas histórias. 50 anos da Escola de Comunicação (ECO) e, daqui a pouco, 100 anos da Universidade Federal do Rio de Janeiro (UFRJ). Apesar disso, o Campus da Praia Vermelha foi palco de diversos momentos marcantes na História do Brasil, e está tendo suas origens esquecidas.

O que muitos alunos não sabem é que o Campus guarda sua origem como segredo, em particular a origem do Palácio Universitário, que mudou de nome algumas vezes desde sua construção em 1852.

Inicialmente chamada de Chácara do Vigário Geral, e de propriedade da Santa Casa de Misericórdia no começo do séc. XIX, foi em 18 de julho de 1841 que, a mando e patrocínio de D. Pedro II que estava sendo coroado neste mesmo dia, as obras que transformariam o local no que vemos ainda hoje se iniciaram.

\begin{abstract}
"Desejando assinalar o fausto dia de minha sagração com a criação de um estabelecimento de pública beneficência: hei por bem fundar um hospital destinado privativamente para tratamento de alienados com a denominação de Hospício de Pedro II, o qual ficará anexo ao hospital da Santa Casa da Misericórdia desta coorte, debaixo da minha imperial proteção" (CALMON, 2002)
\end{abstract}

Desde sua inauguração em 1852 até 1890, o asilo foi denominado Hospício Pedro II, e foi o primeiro hospital psiquiátrico do Brasil e o segundo da América Latina. Décadas depois, em 1948, foi cedido à então Universidade do Brasil. 
Quadro 1 - Linha do tempo Campus Praia vermelha

\begin{tabular}{|c|c|c|c|}
\hline 1852 até 1890 & 1890 até 1937 & 1937 até 1944 & 1948 \\
\hline Hospício Pedro II & $\begin{array}{c}\text { Hospício Nacional } \\
\text { dos Alienados }\end{array}$ & $\begin{array}{c}\text { Hospital Psiquiátrico } \\
\text { Praia Vermelha }\end{array}$ & $\begin{array}{c}\text { Universidade do } \\
\text { Brasil }\end{array}$ \\
\hline
\end{tabular}

Fonte: produção da autora

Para falar sobre a história do Campus é importante contextualizar sua construção. Durante a época de regência da Santa Casa de Misericórdia, o local já era utilizado como enfermaria de forma improvisada atendendo doentes mentais. Apesar disso, o tratamento oferecido era deficiente e em muitos aspectos se igualava ao tratamento oferecido a delinquentes aliado à uma psiquiatria primitiva. O Hospício do Pedro II surgiu então como uma solução para esse ambiente que não contava com assistência adequada.

$\mathrm{O}$ asilo, originalmente planejado para trezentos pacientes de ambos os sexos, começou a funcionar após sua edificação, arquitetada pelos engenheiros Domingos Monteiro, Joaquim Cândido Guillobel e o brasileiro José Maria Jacinto Rebêlo, com cento e quatorze pacientes. Apesar de ainda contar com celas de isolamento e grades, já havia um rascunho do que se transformaria anos mais tarde em terapia ocupacional, com instrumentos musicais, oficinas para trabalhos manuais e ambientes propícios, como pátios arborizados e salas com claridade. Em 1890, o ministro do governo provisório, Aristides Lobo, decretou a separação do hospício da Santa Casa da Misericórdia, e o lugar passou a se chamar Hospício Nacional de Alienados. As mudanças que se deram a partir daí, de acordo com Geovanini et al (1995), foram a criação de uma sessão masculina, e a saída das irmãs de caridade, que antes atuavam como enfermeiras e encobriam maus-tratos sofridos pelos pacientes. Por conta da falta de mão de obra, surgiu uma solução que alterou o curso da psiquiatria e da enfermagem, antes limitadas à reproduzirem os moldes franceses, a Escola Profissional de Enfermeiros e Enfermeiras. Após as três primeiras décadas do século 20, Juliano Moreira inaugurou a psiquiatria no Brasil se inspirando nos esforços de Teixeira Brandão e Nuno de Andrade, que iniciaram o ensino da área no país.

\section{Desenvolvimento}

Essa breve contextualização dos primórdios do Campus, nos leva aos textos de Michel Foucault, que em obras como "História da loucura" e "Microfísica do poder" nos fala como os ditos "alienados" eram levados para longe do convívio em sociedade, como resposta a uma pressão feita pela mesma.

Apesar de Foucault afirmar que o hospital até o século VXIII assume esse papel de separação, exclusão e "morredouro"- já que não se ia para os hospitais a fim de se curar, mas apenas para se ter um local onde morrer - a localização geográfica escolhida para receber o 
Hospital Pedro II, no século XIX, estava a uma distância conveniente do rico subúrbio de Botafogo e do terminal das linhas de bondes que atendiam a essa área.

Além da distância, Philippe-Marius descreveu em 1875 as condições no Hospício em seu artigo "O Hospício de Pedro II e os alienados no Brasil" e cita "os meios de contenção" utilizados:

\begin{abstract}
Os meios de repressão autorizados pelo regulamento incluem: a privação de visitas, de passeios e de outros tipos de recreação. Às vezes, a redução dos alimentos, numa proporção prescrita pelo médico, uma estadia na cela-forte e as duchas. A camisa de força é o único meio de contenção que vimos. Ela é utilizada da mesma forma que nos nossos asilos. (REY, 2012)
\end{abstract}

Analisando, em conjunto com a literatura, a obra cinematográfica "Nise, o coração da loucura", também se percebe o tratamento dado aos pacientes em 1944, época em que Nise passou a trabalhar no Hospital do Engenho de Dentro, e após se recusar a seguir o tratamento da época - que incluía choque elétrico, cardiazólico, insulínico, camisa de força e isolamento - a psiquiatra foi transferida, como "punição", para o Setor de Terapia Ocupacional do Pedro II, onde grande parte do filme se passa, e onde hoje se encontra o Museu do Inconsciente. O que não é tão enfatizado no filme, é que logo após terminar sua especialização, Nise foi aprovada em 1933 em um concurso de psiquiatria, e começou a trabalhar no Serviço de Assistência a Psicopatas e Profilaxia Mental do Hospital da Praia Vermelha, e desde essa época, já não sentia afinidade pelos tratamentos oferecidos pelos hospitais psiquiátricos. O Campus novamente faz parte da História.

\title{
3. Metodologia e resultados
}

O presente artigo buscou observar o conhecimento existente entre os docentes, discentes e servidores da Universidade Federal do Rio de Janeiro (Campus Praia Vermelha) no que diz respeito ao passado do local onde estes atuam, tendo como base o referencial teórico já citado.

Ao questionar alunos e servidores sobre o histórico do Campus, poucos souberam de seu passado. O aluno Felipe Knupp Vieira, do primeiro período do curso de administração da UFRJ, ao ser perguntado sobre a história do Campus disse "ouvi falar que era o mais antigo do Brasil, não sei se isso é verdade, e que D. Pedro estudou aqui” também disse que não costuma ouvir os alunos conversando sobre o assunto. A aluna Guinevere Ramos Gaspari Ribeiro, no oitavo período de comunicação social, acredita que

Por muito tempo o Campus foi sede de um manicômio e dizem que até hoje existem salas com aparelhos que eram usados pra tortura naquela época, e depois foi cedido à Universidade do Brasil e estamos aqui até hoje, dividindo espaço com o Pinel, com o Instituto de Psiquiatria da 
UFRJ, e acho que ainda tem muito resquício disso ai né, claro que em formato muito diferente de como era naquela época, mas acho que ainda acontece muita coisa ruim ali dentro que é parte dessa cultura manicomial.

A aluna também disse que as únicas vezes que conversou sobre o Campus foi fora de sala. $\mathrm{O}$ aluno Bruno Parisoto Lopes, no décimo período do curso de direção teatral, também sabia que ali havia sido um dos primeiros hospitais psiquiátricos do Brasil, citando como ano de inauguração 1920, e que logo depois a UFRJ adquiriu o Campus; entretanto dá mérito ao conhecimento adquirido a uma pesquisa feita sobre a História da loucura no Rio de Janeiro.

Já o servidor Sérgio Ribeiro, que trabalha no local a 14 anos, disse que "antigamente, em 1949, era o tempo dos escravos aqui do instituto". A professora e coordenadora do curso de comunicação Andréia Resende Barreto dá aulas desde 2010 e assumiu que ao entrar para a UFRJ chegou a pesquisar a história do Campus e sabe que Lima Barreto foi internado no Hospício da época; também mencionou que estava presente quando a capela pegou fogo, tendo que sair de sala durante o episódio; fora isso, afirmou não ter conhecimento de outros eventos históricos.

Cabe, portanto, mencionar que hoje o campus da Praia Vermelha acolhe o Instituto Municipal Philippe Pinel, o Centro de Atenção Psicossocial da UFRJ e o Instituto de Psiquiatria da UFRJ. Além desses, algumas iniciativas começaram por parte de alunos e professores a fim de acabar com o estigma que ainda existe acerca dos transtornos mentais, como projetos de extensão que visam conectar os estudantes ao resto da sociedade.

Gilson Carneiro Santos participa do projeto de extensão ParaTodos, coordenado pela professora Marta Simões Peres, há cerca de quatro anos, é formado em sociologia e se trata no IPUB e no famoso "campinho", onde as aulas ocorrem. Ao ser questionado da importância da ocupação do local, o participante relatou que

O fato mais importante do projeto, é que eu me sinto aqui respeitado, acolhido e amado. E amar e ser amado faz um bem enorme à vida e à saúde. O propósito do espaço é tentar criar um link, um laço, entre a universidade, que é pública mas que exclui a sociedade; então o projeto é justamente isso, detonar com os presídios, detonar com as prisões, detonar com os muros e trazer um diálogo, uma relação com o social. Um espaço importante porque no começo do projeto a gente tava numa espécie de campo de batalha, porque havia uma resistência, mas a gente resistiu também, heroicamente, e agora o projeto ta reconhecido em função não da determinação, mas de certa forma o nosso comportamento em ocupar esse espaço, que de uma forma ou de outra estimulou outras pessoas a ocupar também, democratizando a universidade.

Participando do mesmo projeto, Maria Aparecida Lopes do Nascimento também nos conta um pouco da sua sensação e dos benefícios que o projeto trouxe. 
Eu sou uma paciente do Hospital Dia, fui internada no Pinel, hoje eu faço tratamento e acompanhamento com a equipe UFRJ, que me ajuda a me controlar, e eu encontrei aqui no campinho a Marta fazendo teatro, e aquilo me cativou e trabalhando com a árvore e no "tocar na árvore" que me deu aquela força e eu já posso contar uma outra história além daquela que para mim não existiu mas eu vivi, e hoje eu to numa vida nova, eu busco a força na natureza que eu encontrei aqui no campo, e eu gostaria que esse campo não se acabasse nunca, e continuasse assim, porque é muito importante pra mim. Hoje eu não sou mais aquela, é uma extensão, me aceitaram como ser humano e meu coração cresceu mais um pouco, porque coube mais gente. Essa família que eu encontrei aqui é maravilhosa e eu quero continuar brilhando, fazendo serviço com meus colegas porque aqui eu mostro a alegria que ta lá debaixo da tristeza, e eu quero continuar doando, levando praquele que não pode ter o que eu tenho: o amor, a alegria, fazer vocês sorrirem.

Além dos muito relatos de pacientes, também é possível encontrar aqueles feitos por pessoas que inicialmente não tinham nenhuma relação direta com o Campus, como é o caso de Berenice Xavier, que participa do projeto por acreditar na importância da relação entre as pessoas, quaisquer que sejam elas.

Eu sou Berenice Xavier, sou economista, sou artista, atriz, colaboradora do projeto ParaTodos, da Trupe DiVersos e uma coisa que eu tenho a dizer sobre o Campus e as atividades da UFRJ nesse famoso 'campinho', é que o importante aqui, no meu ponto de vista, é que a gente tenha a sensação real de que a externalidade da ação da UFRJ se estende muito, muito além do que a gente pode perceber por uma simples matrícula ou participação como bolsista ou colaborador efetivo. Eu sou uma colaboradora efetiva mas totalmente informal, tô aqui no projeto da Marta porque fui atraída por isso e pela sensação especial de que a externalidade universal, que é a grande pretensão da universidade, se realiza e se concretiza aqui nesse lugar, no campinho, então nós temos uma área de influência muito maior do que a gente pode perceber a primeira vista, onde os fluxos do conhecimento, da troca de conhecimento se dão com muita força, com muita eficácia, então a minha colaboração nesse projeto é que a gente permaneça funcionando aqui, porque é aqui o coração pulsante da UFRJ.

\section{Conclusão}

A partir dos relatos é possível afirmar que há uma real defasagem nas informações que dizem respeito à história do campus, mas existem recursos e eles devem ser pensados em 
prol da relação universidade-sociedade. Um deles é a "ocupação" que se vê atualmente do espaço da universidade para além das salas de aula, e aqui é possível incluir projetos de extensão, como o citado durante a discussão, mas também aulas práticas voltadas para o mundo como ele realmente é, empresas juniores, centros acadêmicos e eventos e cursos realizados pelo corpo acadêmico que também permitam essa ponte entre o ambiente universitário e a população. A partir dessas experiências é possível se valorizar o fazer dentro da universidade, e não apenas o pensar, e prestar atenção na necessidade que surge em conhecer o espaço que se ocupa.

Também é possível relacionar a falta de informação que se tem sobre o campus à falta de zelo e cuidado com o ambiente que habitamos. O local que devia ser tratado com o respeito que se tem à museus e outros espaços de grande importância é frequentemente visto ao léu, com gramado sem ter sido aparado, materiais de uso comum quebrados entre outros problemas.

Por fim, ressalto que além da importância de se conhecer a história do Campus, é necessário que se conheça o que ocorre em seu espaço hoje, para que todos possam, juntos, construir uma universidade e uma cidade melhor, sem preconceitos e com respeito à todo aquele que um dia foi tido como diferente.

\section{Referências}

CALMON, P. O Palácio da Praia Vermelha. UFRJ, Rio de Janeiro, 2002.

FOUCAUlT, M. A História da Loucura na Idade Clássica. Perspectiva, São Paulo, 1997.

FOUCAULT, M. Microfísica do poder. Organização e tradução de Roberto Machado. Edições Graal, Rio de Janeiro, 1979.

GEOVANINI, T. et al. História da Enfermagem - versões e interpretações. 2 ed. Rio de Janeiro: Revinter, 2002.

HOFFBAUER, D. Hospício de Pedro II. Memória da Administração Pública Brasileira. Rio de Janeiro, 2016. Disponível em: http://linux.an.gov.br/mapa/?p=9300

REY, P. O Hospício de Pedro II e os alienados no Brasil (1875). Rev.latinoam. psicopatol. fundam., São Paulo, v.15, n.2, p.382-403, 2012. Disponível em: http://www.scielo.br/scielo.php?script=sci_arttext\&pid=S1415-

$\underline{47142012000200012 \& \operatorname{lng}=e n \& n r m=\text { iso }}$ 
TOLEDO, C. 1964: o golpe contra as reformas e a democracia. Rev. Bras. Hist., São Paulo, v. 24, n. 47, p. 13-28, 2004. Disponível em: http://www.scielo.br/scielo.php?script=sci_arttext\&pid=S0102$\underline{01882004000100002 \& \operatorname{lng}=\text { en\&nrm=iso }}$ 